\title{
Interlocução das políticas públicas ante a gestão de riscos de desastres: a necessidade da intersetorialidade
}

\author{
Interlocution of public policies regarding disaster risk management: \\ the need for intersectoriality
}

Maluci Solange Vieira', Roberta Borghetti Alves'

DOI: 10.1590/0103-11042020E209

RESUMO No Brasil, o modo de realizar a gestão de riscos de desastres mudou a partir da Lei $n^{0} 12.608$ da Política Nacional de Proteção e Defesa Civil (PNPDEC), em 2012, que preza pelo desenvolvimento sustentável por meio da integração de políticas públicas e de suas respectivas estratégias visando à garantia dos direitos humanos. Nesse sentido, a pesquisa analisou as ações de interlocução das políticas públicas ante a gestão de riscos de desastres em uma cidade da região da Foz do Rio Itajaí, Santa Catarina, Brasil. O estudo qualitativo exploratório foi realizado mediante um roteiro de entrevista semiestruturado, respondido por 12 participantes atuantes em 9 diferentes órgãos que colaboram para a gestão de riscos de desastres. A utilização da Grounded Theory permitiu que os dados fossem analisados e discutidos por intermédio do conteúdo das respostas e fundamentos teóricos. Evidenciaram-se a ausência de ações intersetoriais voltadas à vulnerabilidade socioambiental, o enfoque em ações de resposta ao desastre e a dificuldade em dar continuidade aos trabalhos realizados devido às interrupções ocasionadas por mudanças nos cargos políticos. Sugere-se que a vulnerabilidade socioambiental seja trabalhada transversalmente em todas as etapas, articulada entre todos os atores do processo.

PALAVRAS-CHAVE Política pública. Planejamento em desastres. Desastres. Gestão de riscos.

\begin{abstract}
In Brazil, the way to carry out disaster risk management has changed since Ordinance $n^{\circ} 12.608$ of the National Policy on Protection and Civil Defense (PNPDEC), in 2012, which values sustainable development through the integration of public policies and their respective strategies for the guarantee of human rights. This way, the research analyzed the actions of public policy interaction on disaster risk management in a city located in the Foz do Rio Itajaí region, Santa Catarina, Brazil. The qualitative exploratory study was conducted through a semi-structured interview script answered by twelve participants, between employees and managers acting in nine different agencies that collaborate for the management of disaster risks. The use of the Grounded Theory allowed data to be analyzed and discussed through the content of the answers and theoretical foundations. Some topics became evident, such as the lack of intersectoral actions focused on socio-environmental vulnerability, the focus on disaster response actions, and also the difficulty in continuing the work carried out due to the interruptions caused by changes in political administrations. It is suggested that socio-environmental vulnerability be discussed in a transversal way in all stages, articulated among all actors who are part of the process.
\end{abstract}

1 Universidade do Vale do KEYWORDS Public policy. Disaster planning. Disasters. Risk Management.

Itajaí (Univali) - Itajaí (SC)

Brasil.

malluhbt@gmail.com 


\section{Introdução}

Os desastres são acontecimentos que afetam a todos de forma direta ou indireta. Entende-se o desastre como um fenômeno socioambiental que ocorre de forma progressiva, cíclica ou súbita no meio social e excede a capacidade de resposta local, sendo as suas consequências variáveis conforme o contexto social, político e econômico da região em que ocorre ${ }^{1}$.

Entre os anos de 1995 e 2015, 51 milhões de brasileiros foram afetados por desastres, acarretando a classificação do Brasil como um dos dez países do mundo com o maior número de pessoas afetadas por desastres. Ainda em relação à decorrência dos desastres, o estado de Santa Catarina teve um prejuízo de R \$ 17,6 bilhões entre os anos de 1995 e $2014^{2,3}$.

Ante a recorrência de desastres, foram elaborados marcos e acordos internacionais que buscam reduzir o risco de desastres ao redor do mundo. Atualmente, o Marco de Sendai para a Redução do Risco de Desastres, pactuado de 2015 a 2030, destaca-se por instigar práticas inclusivas, acessíveis e intersetoriais, visando ações mais eficazes. Assim, sugere-se a corresponsabilização e a colaboração entre a sociedade civil, setores público e privado, instituições científicas e Organizações Não Governamentais².

Buscando promover a gestão de riscos de desastres, em abril de 2012, foi instituída a Lei Federal $n^{0} 12.608$ referente à Política Nacional de Proteção e Defesa Civil (PNPDEC). A lei ressalta a importância da intersetorialidade das políticas públicas para o planejamento e a execução das atividades de prevenção, mitigação, preparação, resposta e recuperação na gestão de riscos de desastres, um trabalho em cooperação com a Defesa Civil ${ }^{4}$.

Em relação às etapas da gestão de riscos de desastres, pode-se dizer que as ações que buscam evitar os riscos de desastres são entendidas como preventivas, podendo ser estruturais, como a utilização de técnicas de engenharia, ou não estruturais, como as intervenções para a redução da vulnerabilidade.
Quanto à mitigação, a fase corresponde às intervenções realizadas com o objetivo de minimizar os impactos dos desastres. Por meio de oficinas, capacitações e simulações, acontece a preparação para prever e responder aos desastres. As ações emergenciais ocorrem em resposta ao desastre, e a recuperação consiste na administração dos impactos ocorridos após o evento para restabelecer as condições de normalidade ${ }^{\mathbf{5}}$.

A Lei $\mathrm{n}^{\circ} 12.608$ estipula que o município com áreas suscetíveis à ocorrência de desastres, listado no cadastro nacional, deve construir o seu Plano de Contingência de Proteção e Defesa Civil. Desse modo, ressalta-se a importância da relação entre sociedade, política e ciência, assim como destaca-se a necessidade de haver trabalhos publicados que dialoguem sobre a articulação entre as políticas públicas para a gestão de riscos de desastres ${ }^{6}$.

No que consiste a relevância desta pesquisa, salienta-se que, dos 27 mil artigos publicados no mundo, de 2012 a 2016, voltados a temática desastres, somente 7,5\% dos trabalhos apresentaram a palavra 'política' no título, resumo ou entre as palavras-chave ${ }^{7}$. Portanto, a discussão sobre a interlocução entre as políticas públicas mostra-se importante para refletir e produzir mudanças sobre o cenário atual. Assim, a pesquisa buscou analisar as ações de interlocução das políticas públicas ante a gestão de riscos de desastres em uma cidade da região da Foz do Rio Itajaí, Santa Catarina.

\section{Material e métodos}

A investigação exploratória foi escolhida devido à temática ainda ser pouco explorada. Nesse sentido, o artigo se caracteriza como uma pesquisa de campo e qualitativa, por permitir a realização de um levantamento de dados a partir de interpretações e descrições dos entrevistados. Dessa forma, o estudo classifica-se como transversal por possibilitar a análise de dados em um curto período, podendo gerar resultados e mudanças em curto prazo $^{8}$. 
Os critérios de inclusão utilizados para selecionar os participantes foram: a) Trabalhar na gestão ou ser indicado para a entrevista pelo gestor de um órgão que contribua para o processo de gestão de riscos de desastres no município, possibilitando a análise de múltiplas realidades de trabalho; b) Atuar, há pelo menos seis meses, em seu cargo, a fim de que tenha experiência e consiga relatar sobre as atividades realizadas. Acerca do número de participantes, foi adotado o critério de saturação de dados, no qual a quantidade de participantes não foi definida previamente?

Desse modo, houve a saturação dos dados por meio da participação de 12 profissionais, sendo 10 do sexo masculino e 2 do sexo feminino. Conforme o quadro 1, pode-se verificar o local no qual cada participante atuava. A média de idade entre os participantes é de 44 anos, e todos possuem formação em nível superior. A fim de preservar o anonimato dos entrevistados, utilizou-se, no decorrer da entrevista, a letra 'P' para denominar os participantes.

Quadro 1. Local de atuação dos participantes

\begin{tabular}{ll}
\hline Participantes & Local \\
\hline 02 & Corpo de Bombeiros Militar \\
02 & Secretaria Municipal de Saúde \\
02 & Coordenadoria Municipal de Proteção e Defesa Civil - Compdec \\
01 & Secretaria Municipal da Educação \\
01 & Secretaria Municipal de Habitação \\
01 & Planejamento Estratégico Municipal \\
01 & Secretaria Municipal de Urbanismo \\
01 & Secretaria Municipal de Desenvolvimento Social \\
01 & Centro Integrado de Gerenciamento de Riscos e Desastres - Cigerd Regional \\
\hline
\end{tabular}

Fonte: Elaboração própria.

$\mathrm{O}$ instrumento de pesquisa utilizado para a coleta de dados consistiu em um roteiro de entrevista semiestruturado, que, apesar de ter um conjunto de perguntas prévio, permitiu novas indagações pelo pesquisador. Por meio da formulação das perguntas, buscou-se investigar como os serviços que trabalham com a gestão de riscos de desastres planejam e executam as ações de prevenção, mitigação, preparação, resposta e recuperação.

Mediante a autorização prévia dos gestores dos setores supracitados, a pesquisa foi submetida e aprovada, CAAE 90260218.2.0000.0120, pelo Comitê de Ética da Universidade do Vale do Itajaí (Univali) conforme diretrizes para pesquisas realizadas em seres humanos. Houve o esclarecimento do foco da pesquisa para cada participante, bem como dos seus riscos e benefícios, e a entrega do Termo de Consentimento Livre e Esclarecido (TCLE). Os depoimentos foram gravados e transcritos literalmente; como local para a coleta de dados, foi utilizada uma sala privativa no ambiente de trabalho de cada profissional entrevistado.

A análise de dados ocorreu pela Grounded Theory, uma teoria fundamentada nos dados, escolhida com a intenção de compreender o desdobramento da temática a partir dos fenômenos revelados nas entrevistas. As 
entrevistas foram transcritas, codificadas, categorizadas e analisadas com o auxílio do software NVivo 11. A codificação ocorreu por comparação de conteúdo entre as respostas das entrevistas, resultando em categorias em comum. A redução dos dados a conceitos e temáticas foi realizado, e, a partir das categorias e subcategorias que foram elaboradas, os dados teóricos foram adicionados e relacionados para interpretar e discutir os fenômenos expostos ${ }^{10}$.

\section{Resultados e discussão}

A interlocução das políticas públicas ante a gestão de riscos de desastres foi analisada a partir das perspectivas dos participantes. Os resultados foram sistematizados em três categorias, a saber: Prevenção e Mitigação; Preparação e Resposta; e Recuperação.

\section{Categoria 1. Prevenção e Mitigação}

Nota-se, a partir da categoria de Prevenção e Mitigação, que a relação e a comunicação com outros municípios impactam na gestão de riscos de desastres. A troca de informações entre as Defesas Civis das cidades da Foz do Rio Itajaí ocorre, sobretudo, por meio da atualização constante dos níveis dos rios e das chuvas em seus sites.

As ações macrorregionais envolvem 11 cidades da Associação dos Municípios da Foz do Rio Itajaí (Amfri), atendidas pelo Centro Integrado de Gerenciamento de Riscos e Desastres (Cigerd) Regional. A relação entre os municípios é promovida por intermédio de diversas ações, como a construção de um ranking para analisar e elencar as cidades mais desenvolvidas em relação à Lei no ${ }^{0} 12.608$. Além disso, é estimulado que, assim como ocorre na cidade pesquisada, todos os municípios tenham o Plano de Auxílio Mútuo (PAM), uma lei orgânica que permite a ajuda mútua entra as cidades sem gerar improbidade administrativa. Nesse sentido, o P01 nota que:
Os problemas não têm divisa geográfica, as pessoas precisam aprender a trabalhar ele em conjunto, e a nossa cultura é bem atrasada nessa questão, por causa de questões partidárias, interesse dos próprios políticos, interesses pessoais. Há bastante luta em relação a isso. (P01 - Cigerd Regional).

Quanto à construção do Plano de Contingência, acredita-se que a primeira etapa deve ser o mapeamento das áreas de risco e o reconhecimento de quais políticas, setores e serviços existem na cidade. Pensando assim, a Amfri contratou um geólogo que está concluindo o mapeamento usando como base as lacunas da Companhia de Pesquisa de Recursos Minerais (CPRM - Serviço Geológico do Brasil). Em seguida, o município deverá alimentar o Sistema Integrado de Defesa Civil (SisDC) com esses dados, com o auxílio do Cigerd Regional, e só então construir o Plano de Contingência.

A Coordenadoria Municipal de Proteção e Defesa Civil (Compdec) é responsável por realizar o trabalho de monitoramento das áreas de risco, assim, possui uma sala com informações constantes dos rios e imagens de radares e conta também com a participação da comunidade, para que estas possam informar caso haja alguma alteração nessas áreas.

Quanto aos equipamentos e sistemas de alerta, a cidade possui pluviômetros e estações de telemetria que emitem informações a todo momento. Além da captação de recursos pela Prefeitura, Governo Estadual e setor privado, a Compdec pretende aumentar o número de estações de telemetria por meio de recursos provenientes dos Termos de Ajustamento de Conduta (TACs), uma parceria com o Ministério Público.

Os boletins emitidos pela Compdec informam sobre o risco de maré alta, ressacas, precipitação pluviométrica elevada e demais alterações climáticas. Quando um risco é identificado, a Compdec entra em contato com a setorial mais adequada para aquela demanda. No caso de poda de árvores ou da necessidade de remoção de 
rochas que estejam colocando residências em risco, o Corpo de Bombeiros Militar da cidade é acionado.

O setor de Planejamento Estratégico promove reuniões com os demais seguimentos da sociedade, inclusive com a comunidade. A participação da população em oito oficinas realizadas por esse órgão permitiu que fossem ouvidas 500 pessoas diretamente e mais de 2 mil pessoas indiretamente para elaborar o Planejamento Estratégico para os próximos 22 anos, perpassando diferentes gestões municipais. Além disso, o município é um dos pioneiros no País a aliar ao seu planejamento aos Objetivos de Desenvolvimento Sustentável (ODS).

O objetivo da gestão de riscos de desastres deve ser o alcance de um desenvolvimento socioeconômico sustentável ${ }^{3}$. Essa constatação permite que as intervenções na gestão de riscos de desastres considerem a influência que o processo histórico-social tem para a concepção de eventos de desastres.

A Secretaria Municipal de Saúde acredita que quando a pessoa conhece o seu direito pode lutar por ele e diminuir a sua vulnerabilidade, podendo fazer isso por meio da participação ativa nos Conselhos Locais de Saúde. Um tema hoje discutido apenas nos setores de saúde pública e proteção social, a vulnerabilidade socioambiental precisa ser amplamente abordada pelos demais órgãos, pois tem impacto direto sobre a proporção das consequências nos desastres"1.

Um dos objetivos do planejamento estratégico, anteriormente citado, é o de viabilizar a mobilidade urbana, em valores aproximados de R \$ 800 milhões. Entende-se que serão evitados mais de $60 \%$ dos desastres provocados por inundações com essas medidas. Entre as 50 intervenções que serão realizadas está a construção de quatro canais de macrodrenagem, envolvendo as Secretarias Municipais de Obras e de Urbanismo na execução das ações e elaboração dos projetos.

A Secretaria Municipal de Urbanismo entende que deve inibir a ocupação das 51 áreas de risco mediante fiscalização e, quando solicitado pela Compdec, deve apoiar em análises de risco de deslizamento de encostas e desmoronamento de imóveis. Já a Secretaria Municipal de Habitação, quando acionada, participa de vistorias, intervenções, autorizações de retorno, organização de projetos habitacionais conforme as demandas encontradas e informa o Ministério Público sobre os riscos que aquele local oferece aos moradores.

Em parceria com a Compdec, as Secretarias de Urbanismo e Habitação fazem parte do Projeto Vidas, voltado ao monitoramento de áreas de risco e das áreas públicas. Esses setores possuem um grupo no aplicativo WhatsApp, no qual a Polícia Militar está presente; caso seja constatado uma ocupação irregular, o projeto age para impedir. No entanto, como observado pelo P04, a possibilidade de dialogar com essas pessoas sobre o apego ao lugar não é considerada:

Vivem no local não somente aquela família, mas os avós, os pais, as pessoas foram ficando naquele lugar. Então, há um trabalho histórico, antropológico, sociológico e não é fácil para os serviços tirarem uma família de um lugar desse, porque ela tem raízes ali. (P04 - Planejamento Estratégico Municipal).

O mapeamento dos riscos poderia se apresentar como uma oportunidade para a elaboração de projetos voltados à redução da vulnerabilidade 5 . No entanto, não existe um projeto envolvendo diferentes setoriais com enfoque na redução da vulnerabilidade socioambiental; as medidas mencionadas pelos setores culpabilizam a comunidade por estar habitando em locais de risco e ausenta o governo da responsabilidade de assegurar os direitos sociais por meio da efetivação das políticas públicas.

A Secretaria de Assistência Social é envolvida a partir do momento que as famílias começam a viver nas áreas de risco. Em alguns casos, ocorre a remoção dessas pessoas para o aluguel social, embasado no relatório técnico da Secretaria de Habitação e pago 
pelo município. O auxílio-moradia é ofertado de forma paliativa até que se encontre uma solução habitacional definitiva. Entretanto, muitas famílias que foram encaminhadas para o Aluguel Social na enchente de 2008 continuam vivendo desse modo, principalmente pela falta de projetos habitacionais concluídos.

Em 2018, após anos de espera, realizou-se a entrega do conjunto habitacional para abrigar aqueles que vivem em situação de risco - são 496 unidades em um novo loteamento. O terreno foi doado pelo município, e o projeto é do governo federal, pelo programa Minha Casa Minha Vida. A implantação de projetos habitacionais oportuniza os direitos antes negligenciados pelo governo à essa população, como moradia em locais com baixo risco de desastres, mobilidade urbana, saneamento básico e serviços de saúde e educação.

O envolvimento da população na proteção e defesa civil permite a fiscalização, a cobrança de planos de governo e, assim, o empoderamento social' ${ }^{12}$.

Se não tiver empoderamento, participação popular para garantir os seus direitos de moradia, educação, saneamento, ter isso como é seu por direito, não é o Governo que vai garantir. A população precisa entender que ela tem que lutar por isso. (P05 Secretaria Municipal de Saúde).

Uma das formas que a Secretaria de Saúde possui de se aproximar da comunidade é por intermédio da Estratégia Saúde da Família (ESF), que responde à atenção básica no Sistema Único de Saúde (SUS). A equipe da ESF identifica as demandas e potencialidades no território, e quando percebe uma situação de risco, aciona serviços de busca pelo emprego, projetos de extensão da universidade, Secretaria de Assistência Social e o apoio da própria comunidade.

As ações de saúde podem ser promovidas como uma forma de redução de riscos de desastres. Nesse sentido, a organização e a preparação dos serviços de saúde devem ocorrer antes do desastre, pois, além do impacto na saúde da população por doenças, danos físicos e sofrimento psíquico, os desastres também podem danificar estruturalmente os serviços de saúde ${ }^{13}$.

A Compdec realiza ações voltadas à educação, como a Blitz Educativa, com a Agência Nacional de Transportes Terrestres (ANTT), com orientações sobre o transporte de produtos perigosos; e o projeto Defesa Civil nas Escolas, que é dividido em três etapas e atende alunos de toda a rede municipal do $6^{\circ}$ ano ao $9^{\circ}$ ano. Na fase um, tendo o objetivo de trabalhar temas como incêndio, tempestades, gestão de riscos de desastres, plano de evacuação escolar e enchentes, foram atendidas 2.500 crianças em 62 palestras para 93 turmas, já a etapa três consiste na formação dos agentes mirins.

A Compdec espera mudar a cultura das pessoas que vivem em áreas de risco. No entanto, essa reflexão sobre a percepção do risco mostra-se limitada ao esperar que as famílias transformem a sua realidade a partir da informação que a sua moradia oferece riscos, desconsiderando outros fatores, como a questão financeira e o apego. A responsabilidade é transmitida para as pessoas como um ato de doutrinação, deixando de discutir outros pontos que influenciam na construção da vulnerabilidade e que são de responsabilidade do governo ${ }^{14}$.

Integrar a temática de redução de riscos de desastres à escola significa reconhecer que a vulnerabilidade socioambiental é desenvolvida historicamente e que a transformação desse cenário ocorre a partir de ações de diferentes setores em conjunto com a comunidade. Nesse caso, a temática ainda não se encontra integrada ao currículo escolar ${ }^{15}$.

O projeto Defesa Civil nas Escolas pretende estimular a implantação do Núcleo Comunitário de Proteção e Defesa Civil (Nudec) a partir da mobilização das associações de moradores já existentes nos bairros. O Nudec, quando organizado, pode ser um forte instrumento para expressar a voz da comunidade ${ }^{15}$.

Observa-se como o planejamento das ações tem enfoque na resposta ao desastre. Além disso, as ações integradas entre as setoriais 
nessa etapa não trabalham a vulnerabilidade social, ao invés disso, a discussão prioriza debater os riscos ocasionados pelas alterações climáticas.

\section{Categoria 2. Preparação}

A partir da experiência com desastres passados, alguns serviços articularam protocolos e planos para nortear as ações do seu setor durante um desastre. É o caso da Secretaria de Saúde, que possui protocolos ministeriais que indicam o procedimento em casos de epidemia de dengue ou leptospirose em um desastre. $O$ plano de contingência também possui o propósito de nortear as ações a partir das ferramentas disponíveis e deve ser elaborado a partir do trabalho articulado entre os diferentes atores da gestão de riscos de desastres a fim de contemplar uma gestão integral do risco ${ }^{16}$.

No município pesquisado, a Compdec contribuiu para o plano de contingência por intermédio do mapeamento das áreas de risco e por meio de sugestões sobre o papel de cada setorial na gestão de riscos de desastres. A Secretaria Municipal de Educação colaborou para o plano com ideias sobre a metodologia que a Compdec pode utilizar nas escolas e disponibilizou as escolas municipais para que estas possam ser utilizadas como abrigos em desastres.

Nesse sentido, o Corpo de Bombeiros Militar colocou à disposição os seus recursos humanos e materiais. A colaboração da Secretaria de Saúde é a de se responsabilizar por prestar atendimento a todos que estão no abrigo: comunidade, equipe de resgate e voluntários, de modo a dispor de médicos, enfermeiros, profissionais da vigilância sanitária, entre outros.

Além disso, as setoriais se reúnem para praticar simulados e alinhar a função de cada uma das partes. Em 2018, realizou-se um simulado promovido pelo Exército em conjunto com a Prefeitura, Defesa Civil Municipal e Estadual e o Corpo de Bombeiros Militar. P01 do Cigerd Regional reflete sobre essa questão: se não treinar, não se preparar, não vai conseguir ter uma boa resposta. Aí vamos reviver 2008. É complexo porque ainda não se tem entendimento que quando o tempo está bom, tem muito trabalho para fazer.

As ações de preparação geralmente se voltam para atividades de treinamento para situações de alterações climáticas, como ocorre no município pesquisado. Entretanto, a vulnerabilidade socioambiental tem tanto impacto nas consequências de um desastre quanto as mudanças climáticas podem ter, mas não recebe a mesma atenção por parte das setoriais ${ }^{17-19}$.

A formação de funcionários públicos para o atendimento do telefone 199 da Compdec, os cursos de Bombeiro Militar e Comunitário e os simulados de evacuação em escolas e empresas privadas para os casos de desastres são algumas das atividades desenvolvidas pela Compdec e pelo Corpo de Bombeiros Militar para preparar a comunidade. Segundo as leis de proteção e defesa civil, um dos papéis do Corpo de Bombeiros Militar é o de realizar as funções de proteção e defesa civil. Contudo, não há clareza sobre como as ações voltadas à vulnerabilidade socioambiental podem ser executadas. A lei não exige que a Defesa Civil e o Corpo de Bombeiros Militar debatam com a comunidade sobre o impacto que a falta de efetividade das políticas públicas pode ter no risco de desastres ${ }^{\mathbf{1 9}, 20}$.

A vulnerabilidade social não é muito a nossa área, a Defesa Civil delimita o risco e aciona as Secretarias de Desenvolvimento Social e Habitação, que vão se articular para tentar resolver a situação. Identificamos, constatamos a situação e encaminhamos para o órgão responsável competente, desenvolvimento social e vulnerabilidade é a área dos outros, não podemos invadir. (PO2 - Compdec).

Observa-se que a maior parte das atividades realizadas pelas setoriais desse município é executada de modo fragmentado. Assim, cada 
setorial se responsabiliza individualmente pelas ações com as quais possui mais afinidade, ignorando o olhar integral sobre o processo de desastre. Esse é um comportamento contrário ao indicado pelos marcos e acordos internacionais, que prezam pela atuação multissetorial para promover transformações no desenvolvimento e crescimento da sociedade ${ }^{5}$.

O Grupo de Ações Coordenadas (Grac), composto por Secretarias e entidades da cidade, aproxima-se da ideia de trabalho multisetorial, entretanto, as reuniões do grupo ocorrem principalmente nas etapas de resposta e recuperação. São feitas algumas reuniões na normalidade para alinhar o grupo por meio de simulados de mesa e de campo, mas esses encontros não objetivam necessariamente o desenvolvimento de estratégias em comum entre os membros do Grac.

A lista atualizada dos setores envolvidos com o Grac está no plano de contingência da Compdec. O Sistema Comando de Operações (SCO) tem um princípio parecido por se tratar de um grupo que age em uma situação de desastre, assim, estes também se preparam mediante simulados. No entanto, as funções do SCO costumam ser distribuídas entre os membros da Defesa Civil e do Corpo de Bombeiros Militar.

A comunicação pode ser uma ferramenta essencial para mobilizar a comunidade, por isso é essencial que não haja divergência na divulgação das informações. Por meio das redes de comunicação, como o rádio, redes sociais e a televisão, é possível transmitir as informações de base científica de maneira acessível, permitindo que a comunidade compreenda o que deve ser feito a partir de uma situação real ou potencial 5 .

Entende-se, que uma situação de desastre demanda que todas as pessoas estejam preparadas para agir nesse momento de anormalidade. Entretanto, nas atividades promovidas pela Compdec e pelo Corpo de Bombeiros Militar em que a comunidade pode participar, o seu papel se resume ao de espectadora, como em casos de simulados e cursos.

\section{Categoria 3. Resposta e Recuperação}

O alerta à comunidade costuma ser uma das primeiras ações de resposta quando o desastre está prestes a ocorrer, como mencionado pelo P02 da Compdec: "a Defesa Civil vai a campo, usa o megafone da viatura para alertar para que as pessoas evacuem a área ou levantem os seus móveis”. A Compdec disponibilizou buzinas para algumas pessoas que vivem em áreas de risco, que devem ser utilizadas em caso de risco geológico.

Nessa ideia de trabalhar com a população, a Secretaria Municipal de Educação instrui que a rede escolar tenha o aplicativo da Compdec instalado em seus celulares. Além de ser uma das pioneiras no envio de mensagens de texto para as pessoas que moram em áreas de risco, a Compdec tem seu próprio site e perfil nas mídias sociais, como o Twitter e o Facebook, atualizados com a previsão do tempo e o nível dos rios.

Após o desligamento da rede de energia elétrica, o rádio torna-se o principal meio de comunicação, assim, seria importante que alguns membros da comunidade obtivessem acesso aos rádios ${ }^{12}$. Conforme preconizado pela Lei $\mathrm{n}^{0} 12.608$, a Compdec mantém parceria com os profissionais radioamadores da região e possui uma central de rádio em que é realizada a comunicação com as setoriais que possuem rádio, como a Coordenadoria de Trânsito e os serviços de emergência.

A Secretaria de Comunicação Social (Secom) presta apoio durante o desastre direcionando uma equipe de seus profissionais para a sede da Compdec e transmitindo os boletins à imprensa. A Compdec indica um agente para a cadeira de porta-voz no SCO para que todos os setores estejam alinhados e não haja conflito de informações.

Os participantes das Secretarias de Habitação, Educação, Saúde, Urbanismo e do Corpo de Bombeiros Militar acreditam que atualmente a comunicação entre as setoriais está adequada e que não existem problemas quanto a ela. No entanto, os entrevistados da Secretaria de Assistência Social, Planejamento 
Estratégico, Compdec e do Cigerd Regional afirmam que existem falhas na comunicação, sobretudo em relação à transmissão de conhecimento científico, e que este ponto precisa ser melhorado.

A dificuldade em continuar os projetos quando há trocas nos cargos políticos também foi uma questão levantada por um dos participantes. As alianças político-partidárias podem afetar negativamente o processo de gestão de riscos de desastres ${ }^{\mathbf{1 4}}$. Isso ocorre quando ações macrorregionais são evitadas para não auxiliar um município com gestão do partido adversário e nos casos de troca de funcionários após algum processo eleitoral, dificultando o planejamento e a execução de projetos em longo prazo, como afirma o $\mathrm{P01}$ :

A questão das pessoas que estão nas funções no município é dinâmica, elas trocam muito e isso dificulta a comunicação para dar continuidade nos planos e projetos. Não há transição, não existe a comunicação com a outra equipe que vai entrar, não tem essa cultura. (P01 - Cigerd Regional).

Em um momento de anormalidade, o Gabinete do Prefeito convoca os seus Secretários para obter informações e repassar as medidas necessárias por meio de um grupo de trabalho. Em casos de calamidade pública, o prefeito ainda possui a responsabilidade de acionar o Ministério Público e utilizar o Sistema Integrado de Informações sobre Desastres (S2ID), um sistema da União, para que a cidade possa justificar o pedido de recursos.

Já a Compdec aciona inicialmente o Grac e o SCO. A integração de diferentes organizações pode facilitar a comunicação, a padronização das ações, o planejamento, a coordenação da equipe e, assim, reduzir o tempo de reação e a duração da operação ${ }^{21}$. Conforme o P02, representante da Compdec,

todas as instituições passam a trabalhar para a Defesa Civil, ela faz toda a parte de administração, como órgão gestor, e as Secretarias passam a responder pela Defesa Civil.
A Força Tarefa, que além do Corpo de Bombeiros Militar pode contar também com outros grupos de apoio, como o Serviço de Atendimento Móvel de Urgência (Samu), responde pelas ações de salvamento e resgaste em situações de emergência e urgência. Nesses casos, pode haver a necessidade da utilização de botes e lanchas para retirar a população em locais alagados, resgate em águas rápidas, corte de árvores caídas em decorrência de deslizamentos e busca de pessoas após um deslizamento.

Para se ter uma ideia da complexidade, a cidade tem três fases dentro da resposta que ocorrem simultaneamente, Salvamento e Resgate, que é a primeira, a segunda é a Assistência de Saúde e Humanitária, e a terceira fase é o Restabelecimento de cenário. (P01 - Cigerd Regional).

A Secretaria de Assistência Social realiza o cadastro das famílias nos abrigos com o objetivo de identificar quais são as famílias atingidas pelo desastre e as suas respectivas demandas, assim como para evitar situações de corrupção, desvio de donativos e saques indevidos do Fundo de Garantia do Tempo de Serviço (FGTS).

Por meio da comunicação com o Corpo de Bombeiros Militar e com a Compdec, a assistência social consegue verificar quais ruas foram atingidas e comparar os dados para averiguar quais famílias possuem o direito de receber os benefícios garantidos por lei, como materiais para a limpeza das casas, colchões, mantimentos e o fornecimento do Cartão Social na saída do abrigo. No momento do cadastramento nos abrigos, os profissionais devem acolher as famílias, pois muitas delas estão fragilizadas, e precisam coletar os dados para realizar os eventuais encaminhamentos.

No entanto, a atuação da assistência social poderia ser mais ampla e integral a partir do momento que as demais setoriais compreendessem a importância da vulnerabilidade na gestão de riscos de desastres e incorporassem 
a temática na sua agenda de trabalho ${ }^{\mathbf{1 8}}$. Nesse sentido, o P07, que atua na assistência social, afirma que:

as ações feitas ainda são precárias, basicamente só tem a questão do Cartão Social que é fornecido para as famílias em uma questão emergencial, um valor de $R \$ 150,00$ por mês.

A Compdec aciona a Secretaria de Assistência Social para organizar e gerenciar os abrigos, que podem ser escolas municipais, ginásios de esportes, centro de eventos, salas administrativas da prefeitura e salões paroquiais de igrejas. $\mathrm{O}$ abrigo deve ser um espaço de caráter temporário com condições mínimas para uma vida digna, exigindo que haja articulação multiprofissional ${ }^{22}$.

A Secretaria de Educação atua para garantir que as crianças nos abrigos não sejam prejudicadas em relação ao ano letivo. Em relação à saúde, com o apoio de voluntários e das vigilâncias epidemiológica e sanitária, a Secretaria Municipal de Saúde promove consultas médicas, exames, atendimento psicológico, curativos, vacinas, além de reforçar a prevenção por meio de orientações sobre a limpeza das casas e o contato com a água após o desastre. As equipes da ESF auxiliam na verificação das demandas decorrentes do desastre no território.

Na enchente de 2008, a cidade pesquisada recebeu muitos donativos de todo o Brasil. Contudo, por despreparo do município, os donativos foram armazenados de forma inadequada, dificultando a triagem e a distribuição. A ausência de critérios para a compra de materiais e a falta de um método para a realização da triagem dificultam a armazenagem dos donativos e atrasam a organização e a entrega dos kits para a população $\mathbf{2 1}$.

Nesse sentido, orienta-se que as cidades se preparem e busquem o auxílio de instituições que já tenham a expertise em gerenciar os donativos, como a Cruz Vermelha, Lions Clube, Rotary e o Exército Brasileiro. Além disso, a Compdec possui o setor de Logística, responsável por gerenciar as doações. Os municípios podem trabalhar com a opção de registro de preço ao comprar direto do fornecedor e entregar ao cidadão. O gerenciamento de donativos é um ponto que exige preparo, conforme fala do P03 da Compdec:

Houve um problema de logística com o excesso de donativos. O Brasil inteiro foi mobilizado e enviou doações. A separação de tudo naquele momento atrapalhou, pois nessa hora o tempo é muito importante.

Ainda durante o desastre, as principais funções geralmente ficam a encargo dos profissionais que já trabalham nos serviços e de entidades de ajuda humanitária. Entretanto, muitos universitários e membros da comunidade se oferecem para realizar voluntariado nesses eventos. Desse modo, a Compdec mantém uma lista com voluntários pré-cadastrados, distribuindo estes conforme a demanda de cada setor, como visto na fala do P01:

O município deve utilizar o voluntário dentro da sua essência, então um carpinteiro vai ser carpinteiro nesse processo, um médico vai ser médico, porque se a pessoa vem para servir, tem que ser naquilo que ela é melhor, até para ela não correr riscos. (P01 - Cigerd Regional).

Além de ativos humanos, no momento de resposta ao desastre, é comum que sejam disponibilizados pelas setoriais os seus veículos e demais equipamentos, como guindastes e rádios HTP. A coordenação desses instrumentos é feita pela Compdec, possibilitando, principalmente, o auxílio em ações de resgate de pessoas e na retirada de móveis. Após o desastre, ocorre a limpeza da cidade, na qual a Secretaria Municipal de Obras e a empresa contratada para realizar a limpeza urbana trabalham na recolha de entulhos e limpeza das ruas para que se possa iniciar o trabalho de reconstrução.

Percebe-se que, ao contrário do que a Lei $\mathrm{n}^{\mathrm{o}} 12.608$ preconiza, as atividades descritas pelos participantes não demonstram que existe 
corresponsabilização entre a comunidade e os setores público e privado. A comunidade raramente é ouvida ou convidada a fazer parte da construção do planejamento das atividades de gestão de riscos de desastres.

\section{Considerações finais}

O estudo evidenciou quais são algumas das ações intersetoriais executadas pelas políticas públicas analisadas para a redução de riscos de desastres no município pesquisado, destacando principalmente a parceria entre a Defesa Civil com o setor de Educação e com o Corpo de Bombeiros Militar. As atividades desenvolvidas entre esses órgãos voltam-se, principalmente, para o diálogo com a comunidade para evitar situações de ocupação irregular e informar sobre como agir em um desastre.

Nessa direção, o estudo demonstra que, na cidade pesquisada, o desastre não é discutido como um fenômeno socialmente construído a partir do desenvolvimento da vulnerabilidade. Percebe-se que esse assunto é evitado pelos demais serviços, que atribuem a responsabilidade à Secretaria de Assistência
Social. A partir desse resultado, espera-se que a temática seja trabalhada em todas as etapas da gestão de riscos de desastres de forma transversal, articulada entre todos os atores desse processo. A implantação de protocolos integrados de atendimento pode favorecer essa intervenção intersetorial.

Por fim, observa-se que há divergência quanto às respostas sobre a qualidade da comunicação entre as organizações. A diversidade de opiniões pode ocorrer devido a parte dos participantes ocuparem 'cargos de confiança'. O discurso político tende mais a ocultar do que revelar as ações realizadas, e este aspecto se apresenta como uma limitação para a pesquisa. Portanto, sugere-se que sejam executados estudos em nível macrorregional para analisar se as ações realizadas por cidades vizinhas possuem articulação entre si e como os interesses políticos interferem nessas relações.

\section{Colaboradoras}

Vieira MS (0000-0001-8427-5762)* e Alves RB (0000-0002-1866-699X)* contribuíram igualmente para a elaboração do manuscrito. 


\section{Referências}

1. Favero E, Sarriera JC, Trindade MC. O desastre na perspectiva sociológica e psicológica. Psicol. estud. 2014; 19(2):201-209.

2. United Nations Office for Disaster Risk Reduction. The human cost of weather-related disasters 19952015. Geneva: UNISDR; 2015.

3. Universidade Federal de Santa Catarina, Centro Universitário de Estudos e Pesquisas sobre Desastres. Relatório de danos materiais e prejuízos decorrentes de desastres naturais no Brasil: 1995 - 2014. Florianópolis: UFSC; CEPED; 2016.

4. Brasil. Lei $\mathrm{n}^{\circ} 12.608$, de 10 de abril de 2012. Institui a Política Nacional de Proteção e Defesa Civil - PNPDEC; dispõe sobre o Sistema Nacional de Proteção e Defesa Civil - SINPDEC e o Conselho Nacional de Proteção e Defesa Civil - CONPDEC; autoriza a criação de sistema de informações e monitoramento de desastres; altera as Leis nos 12.340 , de 10 de dezembro de 2010, 10.257, de 10 de julho de 2001, 6.766, de 19 de dezembro de 1979, 8.239, de 4 de outubro de 1991, e 9.394, de 20 de dezembro de 1996; e dá outras providências. Diário Oficial da União. 10 Abr 2012.

5. Universidade Federal de Santa Catarina, Centro Universitário de Estudos e Pesquisas sobre Desastres. Gestão de riscos e de desastres: Contribuições da psicologia. Florianópolis: UFSC; CEPED; 2010.

6. Nogueira FR, Oliveira VE, Canil K. Políticas públicas regionais para gestão de riscos: $\mathrm{O}$ processo de implementação no ABC, SP. Ambient. soc. 2014; 17(4):177194.

7. Elsevier. A Global Outlook on Disaster Science. Amsterdam: Elsevier; 2017.

8. Fontelles MJ, Simões MG, Farias SH, et al. Metodologia da pesquisa científica: Diretrizes para a elaboração de um protocolo de pesquisa. Rev. Paran. Med. 2010; 2(24):57-64.
9. Fontanella BJB, Ricas J, Turato ER. Amostragem por saturação em pesquisas qualitativas em saúde: Contribuições teóricas. Cad. Saúde Pública. 2008; 24(1):17-27.

10. Nico LS, Bocchi SCM, Ruiz T, et al. A Grounded Theory como abordagem metodológica para pesquisas qualitativas em odontologia. Ciênc. Saúde Colet. 2007; 12(3):789-797.

11. Londe LR, Marchezini V, Conceição RS, et al. Impactos de desastres socioambientais em saúde pública: Estudos dos casos dos Estados de Santa Catarina em 2008 e Pernambuco em 2010. Rev. bras. estud. popul. 2015; 32(3):537-562.

12. Assumpção RF, Séguin E, Kligerman DC, et al. Possíveis contribuições da integração das políticas públicas brasileiras à redução de desastres. Saúde debate. 2017 ; $41(2): 39-49$.

13. Shoaf K. Organizing the health sector for response to disasters. Ciênc. Saúde Colet. 2014; 19(9):3705-3715.

14. Valencio N, Gonçalves JC, Marchezini V. Colapso de barragens: aspectos sócio-políticos da ineficiência da gestão dos desastres no Brasil. In: Valencio N, Siena M, Marchezini V, et al., organizadores. Sociologia dos Desastres: construção, interfaces e perspectivas no Brasil. São Carlos: Rima; 2009. p. 160-175.

15. Rosa TS, Mendonça MB, Monteiro TG, et al. A educação ambiental como estratégia para a redução de riscos socioambientais. Ambient. soc. 2015; 18(3):211230.

16. Noal DS, Vicente LN, Weintraub ACAM, et al. Estratégia de Saúde Mental e Atenção Psicossocial para Afetados da Boate Kiss. Psicol. cienc. prof. 2016; 36(4):932945 .

17. Díaz GE. Puesta en práctica de una política de desastres: Los instrumentos de la gestión de riesgos en México. Bulletin de l'institut français d'études andines. 2014; 43(3):611-632. 
18. Santos R. Gestão de desastres e política de assistência social. Rev. katálysis. 2012; 15(1):32-40.

19. Silva JCB, Menezes JA. O risco de desastre e as cidades: uma análise discursiva sobre práticas em Defesa Civil. Rev Ciênc Hum. 2016; 50(2):528-547.

20. Santos FG, Acordi CF. Competência legislativa do Corpo de Bombeiros Militar de Santa Catarina acerca dos desastres naturais. Rev Ordem Púb. Defesa Soc. 2016; 9(1):47-162.

21. Manso DF, Suterio R, Belderrain MCN. Estruturação do problema de gerenciamento de desastres do es- tado de São Paulo por intermédio do método Strategic Options Development and Analysis. Gest. Prod. 2015; 22(1):4-16.

22. Costa FG, Flauzino RF, Navarro MBMA, et al. Abrigos temporários em desastres: A experiência de São José do Rio Preto, Brasil. Saúde debate. 2017; 41(2):327337.

Recebido em 03/09/2019

Aprovado em 18/02/2020

Conflito de interesse: inexistente

Suporte financeiro: não houve 